\title{
GMR
}

\section{Correlation between adiponectin and hemorrhagic shock in mice}

\author{
X. Gong, Y. Liu, S. Yao, J.F. Zheng, F. Wan, X.D. Xiang and X.P. Chai \\ Department of Emergency, The Second Xiangya Hospital of Central South University, \\ Changsha, China \\ Corresponding author: X.P. Chai \\ E-mail: chaixiangping1010@163.com
}

Genet. Mol. Res. 15 (1): gmr.15017037

Received August 10, 2015

Accepted October 20, 2015

Published February 5, 2016

DOI http://dx.doi.org/10.4238/gmr.15017037

ABSTRACT. The aim of this study was to explore the relationship between adiponectin (ADPN) and hemorrhagic shock (HS) and the recovery after HS. This is significant for further understanding of the pathophysiological processes of HS and the development of better treatments. In total, 72 male C57BL/6 mice were assigned randomly to three groups: control, HS, and recovery $(\mathrm{N}=24)$. The HS mouse model was constructed by hemorrhage of the carotid artery and recovery was achieved by tail vein injection of Ringer's solution. The level of ADPN in the peripheral blood of mice before and after recovery was detected by enzyme-linked immunosorbent assay. Compared to control, HS mice showed significantly decreased ADPN levels with the extension of HS time while the level of ADPN in recovery mice increased significantly and remained high. The variation of ADPN levels was closely associated with the occurrence of HS in mice and their recovery, suggesting that ADPN might act as a biomarker of inflammation and have potential for the treatment of HS.

Key words: Adiponectin; Inflammation; Hemorrhagic shock; Cytokines; Mean arterial pressure; Serum 


\section{INTRODUCTION}

Hemorrhagic shock (HS) refers to shock caused by a large amount of blood loss and is commonly seen in trauma-induced bleeding, peptic ulcer hemorrhage, esophageal variceal bleeding, and bleeding caused by obstetrical and gynecological diseases (Determan Jr. et al., 2014; Luetke et al., 2014). Previous research has shown that HS has a high rate of mortality; approximately 5.8 million people in the world die from trauma every year and $50 \%$ of these cases are due to HS (Jacob and Kumar, 2014; Liu et al., 2014). HS is induced by many factors, including high rate of blood loss, severe vomiting or diarrhea, intestinal obstruction, or profuse sweating. Factors that result in rapid blood loss (over $20 \%$ of whole blood) will lead to shock, and death will occur quickly when the content of blood loss accounts for more than $50 \%$ of whole blood (Bennetts et al., 2014; Williams et al., 2014). HS is accompanied by many complications, the most evident of which is disseminated intravascular coagulation, which leads to the dysfunction of circulatory (and other internal organ) function, secondary fibrinolysis and consumptive coagulopathy. These complications will result in shock, hemorrhage, thrombosis, and hemolysis (Yang et al., 2013; Ogaki et al., 2014). Therefore, various means should be employed in the treatment of HS, such as ensuring airway ventilation, providing endotracheal intubation and mechanical ventilation, and conducting immediate hemostasis (Ogaki et al., 2014; Zhao et al., 2014). Adiponectin (ADPN) has a pronounced effect on vascular endothelial function; thus, much attention has and should be paid to the relationship between ADPN and HS (Lim et al., 2014).

ADPN, also called Acrp30, apM1, AdipoQ, and GBP28, is an important protein that exists in three forms in the serum: trimer, hexamer, and a high molecular weight form (Phillips and Kung, 2010; Liu and Liu, 2014). ADPN possesses insulin-sensitizing, anti-inflammatory, anti-atherogenic, and antiangiogenic properties, among which the anti-inflammatory effect has been widely confirmed (Gu et al., 2013; Fiaschi et al., 2014). Recent investigations have revealed that HS may induce hypoxia, which can result in changes in cell morphology and metabolism, concluding in an inflammatory response (Qiang et al., 2013). In addition, hypoxia can cause sepsis, adult respiratory distress syndrome, or multiple organ dysfunctions if the severe inflammatory response persists (Fry, 2012; Lakshminarayana and Kahn,

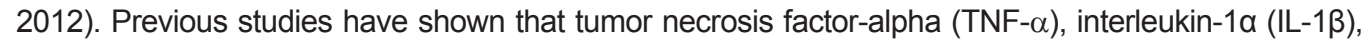
IL-6, and IL-8 play major roles in the inflammatory response after HS (Douzinas et al., 2011; Sonnier et al., 2011). There is also evidence showing that ADPN is vital to chronic inflammation by modulating the phenotypes and functions of macrophages (Ohashi et al., 2012). In adipose tissue, there are two types of macrophages, classic (M1) and alternative (M2), that are classified based on their expression and function of cytokines (Devaraj and Jialal, 2011). M1 macrophages mainly secrete TNF- $\alpha$, IL-1, and IL-6, while M2 macrophages can produce IL-10, an anti-inflammatory cytokine (Baker et al., 2011). It has been found that ADPN can inhibit metalloproteinase-1 by expression of IL-10 and protect vascular injury induced by ischemia in the retina by preventing the production of TNF- $\alpha$ (Ohashi et al., 2012). The present study aimed to investigate the significance of the role of ADPN in the pathophysiological processes of HS in order to provide better treatment options for HS.

\section{MATERIAL AND METHODS}

\section{Ethics statement}

All animal procedures were conducted after approval from the Medical Ethics Review Board of the Second Xiangya Hospital, Central South University (Changsha, China). Each 
procedure was conducted in accordance with the animal guidelines and protocols approved by the Institutional Animal Use and Care Committee. All efforts were made to minimize the number of animals used and their suffering in the study.

\section{Grouping design}

This study was conducted on 72 male C57BL/6 mice (aged 8-10 weeks; weight = $209 \mathrm{~g}$ ) purchased from the animal laboratory at the Second Xiangya Hospital, Central South University (Changsha, China). The C57BL/6 mice were assigned randomly to three groups: 1) control group (group $A, N=24$ ); 2) HS group (group $B, N=24$, intraperitoneal anesthesia and carotid artery hemorrhage to shock); 3) recovery group (group $\mathrm{C}, \mathrm{N}=24$, intraperitoneal anesthesia, carotid artery hemorrhage and tail vein injection of Lactated Ringer's solution for recovery).

\section{Animal model construction}

The mice in each group were anaesthetized using chloral hydrate $(300 \mathrm{mg} / \mathrm{kg})$ containing atropine by intraperitoneal injection. The mean arterial pressure (MAP) was detected by applying noninvasive blood-pressure monitors for animals (BP-98A, Softron, Japan). The right carotid artery was ligated at the distal end of the heart with cannulation using a 30-G detaining needle. The mice were exsanguinated slowly to shock while using a noninvasive blood-pressure monitor (MAP: $35 \pm 5 \mathrm{mmHg}$ ) with the volume of hemospasia recorded. The right carotid artery was ligated following hemospasia. The left jugular vein was separated and exposed, fixed with a cannula inserted (30-G detaining needle), and connected with a micro-syringe pump (WZS-50F6, Smiths Medical Instruments, China). With the HS model constructed and the shock status maintained for 90 min, Lactated Ringer's solution was delivered at a constant speed by tail vein for $15 \mathrm{~min}$. The volume of infused solution was twice that of hemospasia. After the infusion, the left jugular vein was ligated and the incision was sutured.

\section{Hematoxylin and eosin (H\&E) staining}

The kidney, lung and intestinal tissue samples in groups B (24 h after hemospasia) and A were obtained and immediately fixed in $4 \%$ paraformaldehyde solution. The samples were rinsed with phosphate-buffered saline and dehydrated with ethanol. Vitrification was performed using a mixture of pure ethanol and xylene, and the samples were then immersed in paraffin. The paraffinembedded samples were cut into thick histological sections, baked, dewaxed, hydrated, stained with H\&E, dehydrated with ethanol, vitrified with xylene, and sealed with gum. Finally, the stained sections were stored at room temperature.

\section{Blood sample collection and ADPN level detection}

A blood sample $(500 \mu \mathrm{L})$ from group A was collected by tail vein after the tail cut. For group $\mathrm{B}$, the blood sample $(500 \mu \mathrm{L})$ was obtained at 4 time points $(3,6,12$, and $24 \mathrm{~h})$ after the shock status was maintained for 90 min. For group $C$, the blood sample $(500 \mu \mathrm{L})$ was also collected at 4 time points $(3,6,12$, and $24 \mathrm{~h})$ after resuscitation. The blood samples were stored in a heparinized Eppendorf tube $(1.5 \mathrm{~mL})$ for further study. Samples were centrifuged at $2000 \mathrm{~g}$ for $5 \mathrm{~min}$ at $4^{\circ} \mathrm{C}$, and the supernatant was placed in an Eppendorf tube and stored at $-80^{\circ} \mathrm{C}$. Total ADPN level in serum was measured using an enzyme-linked immunosorbent assay (ELISA) provided by Abbott (Japan). 


\section{Statistical analysis}

All calculations were performed with the SPSS software (version 17.0, SPSS Inc., Chicago, IL, USA). Data are reported as means \pm standard deviation. Comparisons among groups were analyzed by the Student $t$-test. $\mathrm{P}<0.05$ was considered significant.

\section{RESULTS}

\section{Changes in blood pressure}

After bloodletting, MAP was significantly lower in group B than in group A (32.50 \pm 1.92 and $62.50 \pm 3.78 \mathrm{mmHg}$, respectively; $\mathrm{P}<0.01$ ). For the first $30 \mathrm{~min}$ of $\mathrm{HS}$, the blood pressure in group B showed a downward trend. After $30 \mathrm{~min}$ of HS, a stable hypovolemic state was observed after a slight raise in blood pressure in group B. The blood pressure of mice in group $\mathrm{C}$ gradually increased 90 min after treatment with Lactated Ringer's solution through the jugular vein. After the treatment $(150 \mathrm{~min})$, the blood pressure of mice in group $\mathrm{C}$ returned to levels similar to those observed in the mice in group $\mathrm{A}$ (Table 1 and Figure 1).

Table 1. Mean arterial pressure (MAP) of mice at different time points after shock treatment for 90 min (group B) and after recovery (group C).

\begin{tabular}{|c|c|c|c|c|c|}
\hline \multirow{2}{*}{ Postoperative time (min) } & \multirow[b]{2}{*}{ Group $A(N=24)$} & \multicolumn{2}{|l|}{$\mathrm{MAP}(\mathrm{mmHg})$} & \multirow{2}{*}{$\mathrm{F}$} & \multirow{2}{*}{$\mathrm{P}$} \\
\hline & & Group B $(N=24)$ & Group $C(N=24)$ & & \\
\hline 0 & $62.9 \pm 3.81$ & $33.3 \pm 2.63^{*}$ & $30.4 \pm 1.15^{\star \#}$ & 1029 & $<0.01$ \\
\hline 10 & $63.3 \pm 2.11$ & $30.6 \pm 2.29^{*}$ & $36.5 \pm 1.75^{\star \#}$ & 1714 & $<0.01$ \\
\hline 20 & $61.6 \pm 2.06$ & $28.5 \pm 3.52^{*}$ & $43.8 \pm 3.91^{* \#}$ & 618.2 & $<0.01$ \\
\hline 30 & $63.8 \pm 2.35$ & $28.2 \pm 3.65^{*}$ & $45.9 \pm 3.26^{* \#}$ & 997.2 & $<0.01$ \\
\hline 60 & $62.8 \pm 2.61$ & $32.4 \pm 3.52^{*}$ & $54.6 \pm 2.50^{\star \#}$ & 590.6 & $<0.01$ \\
\hline 90 & $62.4 \pm 2.38$ & $34.7 \pm 3.20^{*}$ & $58.8 \pm 2.84^{* \#}$ & 681.4 & $<0.01$ \\
\hline 120 & $61.8 \pm 3.37$ & $36.3 \pm 2.47^{*}$ & $60.4 \pm 1.48^{\star \#}$ & 753.1 & $<0.01$ \\
\hline 150 & $62.5 \pm 3.96$ & $34.8 \pm 4.39^{*}$ & $61.3 \pm 1.46^{\#}$ & 476.0 & $<0.01$ \\
\hline
\end{tabular}

${ }^{*} \mathrm{P}<0.05$, compared with group $\mathrm{A}$; $\mathrm{P}<0.05$, compared with group $\mathrm{B}$; $\mathrm{F}$ : a statistical value of analysis of variance.

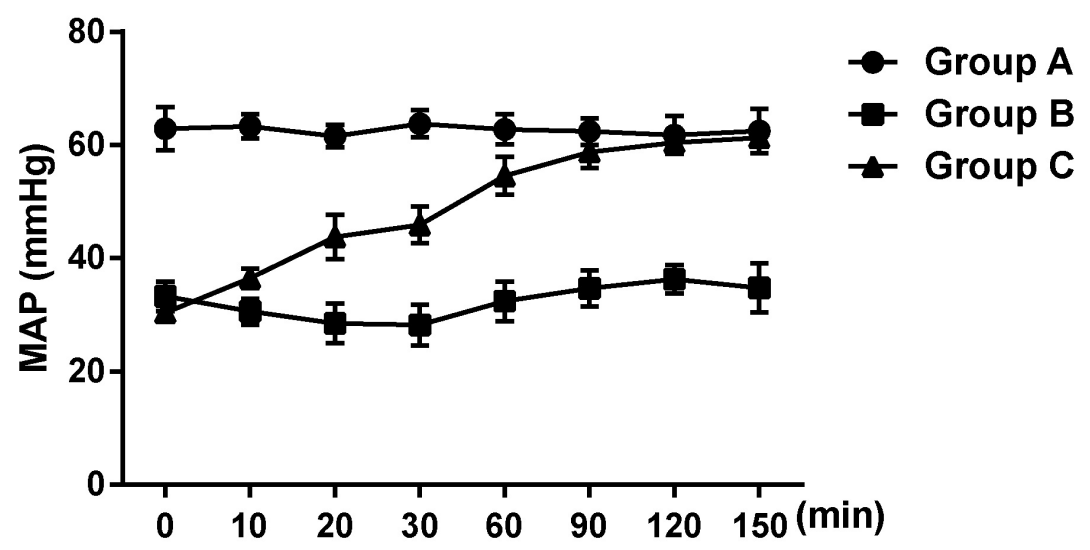

Figure 1. Changes of mean arterial pressure (MAP) of mice at different time points in the three groups. Group A: control group; group B: shock group; group C: recovery group. 


\section{Pathological changes}

H\&E staining was conducted to detect inflammatory changes in major organs of mice in groups A and B. Figures 2, 3, and 4 show the comparison of pathological changes in kidney, lungs and intestinal tract, respectively, between groups $A$ and $B$. Compared with group A, the kidney, lungs and intestinal tract of the mice in group B appeared ischemic. Under the microscope, we observed endothelial cell swelling in kidney (Figure 2), pulmonary interstitial edema and evident inflammatory cell infiltration in lungs (Figure 3), and intestinal mucosal injury (Figure 4) in the mice in group B.
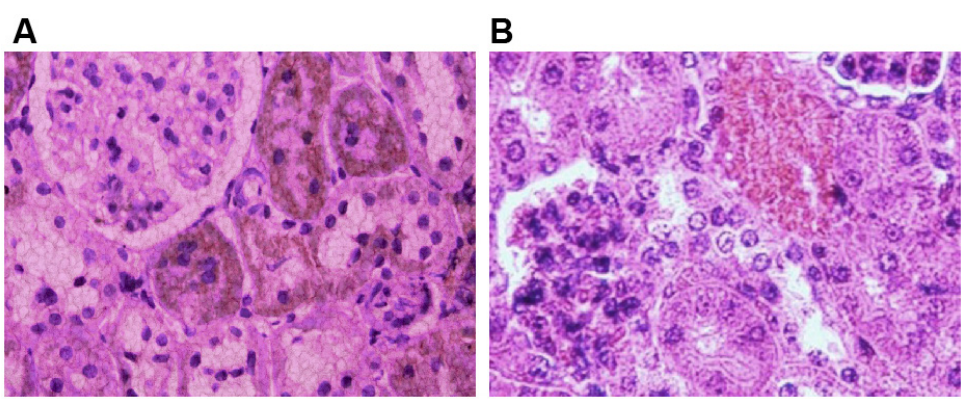

Figure 2. Pathological sections of kidney. A. Control group. B. Shock group; arrow: swelling of kidney epithelial cell of mice in the shock group (200X).

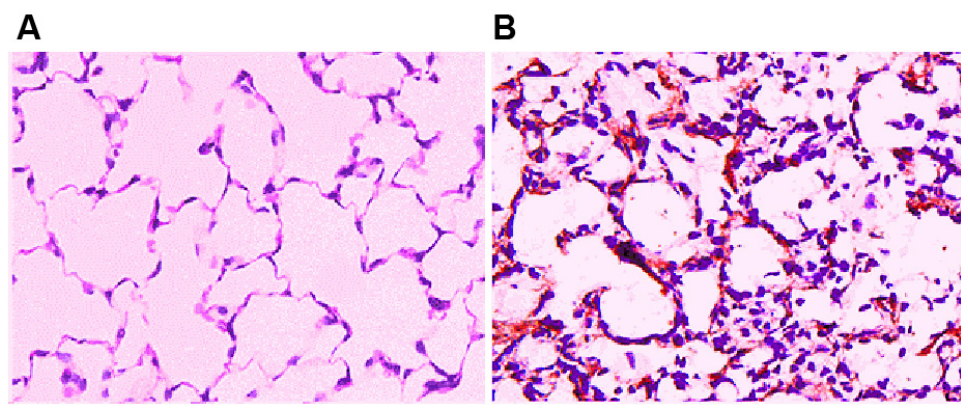

Figure 3. Pathological sections of lungs. A. Control group. B. Shock group; arrow: interstitial pulmonary edema, inflammatory cell infiltration of mice in the shock group (200X).

A

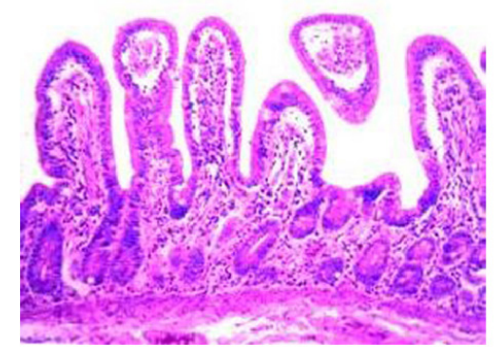

B

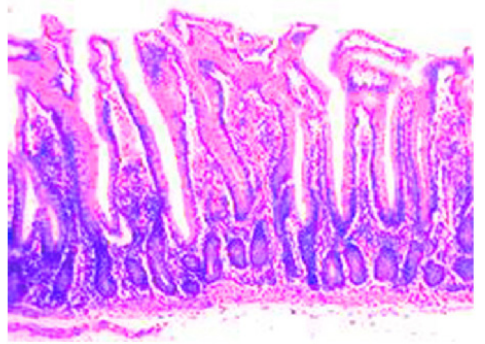

Figure 4. Pathological sections of intestinal tract. A. Control group. B. Shock group; arrow: Intestinal tract mucosal injury of mice in the shock group (200X). 


\section{Serum ADPN levels}

The ADPN levels in the peripheral blood of mice in group B were significantly higher than those in group A in the early stages of HS (3 $\mathrm{h}$ after bloodletting). As shown in Table 2, ADPN levels decreased significantly with the extension of $H S$ time $(P<0.05)$. In contrast with that in group $B$, the serum level of ADPN in group $\mathrm{C}$ was significantly higher in the first $3 \mathrm{~h}$ after recovery treatment with Lactated Ringer's solution. ADPN levels continued to increase for $24 \mathrm{~h}$ after recovery treatment (Table 2 and Figure 5). At all time points, the ADPN levels in group $\mathrm{C}$ were significantly higher than those in groups $A$ and $B(P<0.05$; Table 2$)$.

Table 2. Adiponectin (ADPN) levels in peripheral blood of mice at different time points after shock treatment for $90 \mathrm{~min}$ (group B) and after recovery (group C).

\begin{tabular}{l|r|c|c|c|c}
\hline \multirow{2}{*}{ Postoperative time $(\mathrm{h})$} & \multicolumn{3}{|c|}{ ADPN $(\mathrm{pg} / \mathrm{mL})$} & \multirow{2}{*}{ F } & \multirow{2}{*}{ P } \\
\cline { 2 - 5 } & Group A (N = 24) & Group B (N =24) & Group C (N =24) & & \\
\hline 3 & $58.535 \pm 8.061$ & $72.119 \pm 10.100^{*}$ & $85.320 \pm 8.114^{* \#}$ & 55.47 & $<0.01$ \\
\hline 6 & $58.668 \pm 5.673$ & $59.303 \pm 16.223$ & $96.482 \pm 9.750^{* \#}$ & 86.45 & $<0.01$ \\
\hline 12 & $66.490 \pm 7.863$ & $25.277 \pm 8.308^{*}$ & $107.374 \pm 14.698^{\text {*\# }}$ & 349.7 & $<0.01$ \\
\hline 24 & $61.129 \pm 7.431$ & $13.293 \pm 4.640^{*}$ & $110.510 \pm 11.897^{\text {*\# }}$ & 779.4 & $<0.01$ \\
\hline
\end{tabular}

${ }^{*} \mathrm{P}<0.05$, compared with group $\mathrm{A}$; $\mathrm{\#}<0.05$, compared with group $\mathrm{B}$; $\mathrm{F}$ : a statistical value of analysis of variance.

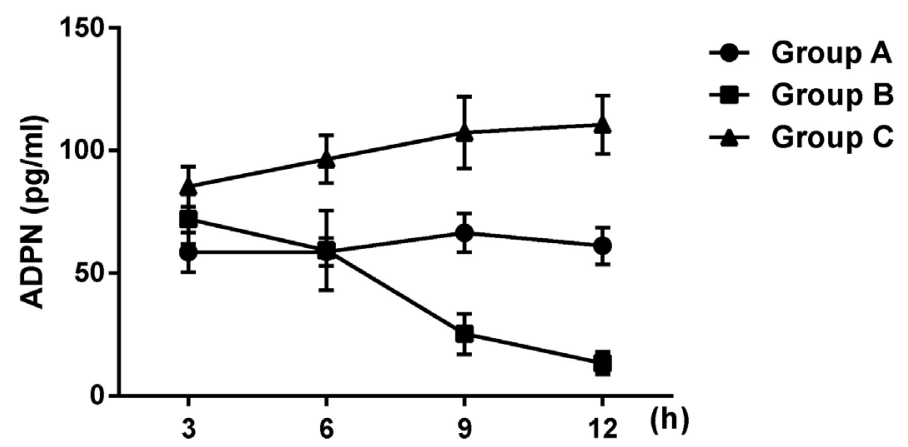

Figure 5. Changes of the adiponectin (ADPN) level in the three groups. Group A: control group; group B: shock group; group C: recovery group.

\section{DISCUSSION}

Our results show that the peripheral blood levels of ADPN in mice progressively decrease post-HS but increase after recovery treatment. It has been shown that ADPN can inhibit the production and release of TNF- $\alpha$ and can relieve inflammation (Jung et al., 2014; Kumpatla et al., 2014). The primary mechanism by which ADPN inhibits inflammation is by inhibiting the production of proinflammatory cytokines and stimulating the release of anti-inflammatory cytokines (Coimbra et al., 2014; Lisowska et al., 2014). Many studies have documented the involvement of ADPN in the termination of inflammation by at least two mechanisms: the first is through the inhibition of the function of mature macrophages and the second is the growth of granulocyte-monocyte 
progenitor cell lines. The former mechanism plays an important role in acute inflammation while the latter mechanism plays a major role in chronic inflammation in order to avoid excessive immune response (Antonopoulos et al., 2014; Cao et al., 2014; Li et al., 2015). Additionally, the findings in our present study demonstrate that the serum level of ADPN in mice increase in the early period of HS, which is in accordance with the varying trend of IL-37 in the same HS model. This suggests that the transient rise of ADPN in the early stages of HS may be adaptive. In addition, the level of ADPN progressively decreased with the extension of HS time and progressively increased after the recovery treatment of HS mice. Therefore, we hypothesize that a reduction in ADPN is involved in full-body pathophysiological changes after induction of HS (Kim et al., 2014; Lian et al., 2015; Safai et al., 2015). We found that ADPN could be used as an anti-inflammatory cytokine, which can instantly and effectively reverse HS and its concomitant pathophysiological changes in the body during post-shock recovery. Moreover, ADPN levels positively correlated with HS prognosis.

Our study showed that the expression of IL-1, IL-6, and TNF- $\alpha$ increased significantly in peripheral blood in the early stage of HS. IL-I $\beta$ is a proinflammatory cytokine that is involved in many pathological processes of ischemia and hypoxia, such as HS (Mishra et al., 2012). Recent studies have shown that after induction of HS in mice, the production of monocyte macrophages leads to an increase in IL-1 $\beta$ levels, and it has been confirmed that HS and recovery could increase the production of IL-1 $\beta$ (Petrasek et al., 2012; Mishra et al., 2012). Our study revealed that the production of IL-1 $\beta$ in the serum of mice remarkably increased after HS. IL-6, a common inflammatory cytokine, can directly act on vascular endothelial cells and increase their permeability, which can cause a strong inflammatory response (Neurath and Finotto, 2011; Covarrubias and Horng, 2014). IL-6 is involved in a number of biological processes, including inflammation, oncogenesis, hematopoiesis, and immune regulation (Kishimoto, 2010). In addition, TNF- $\alpha$ also plays an important role in the development of the immune system, inflammatory reactions, programmed cell death, and lipid metabolism (Horiuchi et al., 2010). TNF- $\alpha$ can stimulate production of cytokines, resulting in the release of active oxygen and a variety of enzymes, and promote the aggregation and activation of granulocytes in the capillaries, which leads to inflammation and damage to tissues and organs after shock (Wu and Zhou, 2010; Li et al., 2012). To a certain extent, the inhibition of IL-1 $\beta$, IL-6, and TNF- $\alpha$ in early HS can inhibit further pathogenic effects of shock. After HS, the production of inflammatory factors increases rapidly, resulting in a decrease in inflammatory cytokines similar to that observed with ADPN. Following the recovery treatment of postoperative infusion of Lactated Ringer's solution, there is a decrease in the production of inflammatory factors and a progressive increase in the serum content of ADPN.

There are some notable limitations to our study. For instance, we only elucidate the relationship between ADPN serum levels and HS (and recovery) using ELISA detection in peripheral blood. Further research is needed to verify whether ADPN can be used as an index for early diagnosis and prognosis of HS. In conclusion, the changes in ADPN levels correlated with the occurrence of HS as well as the recovery from HS in mice, suggesting that ADPN could be a potential biomarker of inflammation and HS and could potentially be used in the treatment of HS.

\section{Conflicts of interest}

The authors declare no conflict of interest.

\section{ACKNOWLEDGMENTS}

We would like to acknowledge the reviewers for their helpful comments on this paper. 


\section{REFERENCES}

Antonopoulos AS, Margaritis M, Coutinho P, Digby J, et al. (2014). Reciprocal effects of systemic inflammation and brain natriuretic peptide on adiponectin biosynthesis in adipose tissue of patients with ischemic heart disease. Arterioscler. Thromb. Vasc. Biol. 34: 2151-2159. http://dx.doi.org/10.1161/ATVBAHA.114.303828

Baker RG, Hayden MS and Ghosh S (2011). NF-kB, inflammation, and metabolic disease. Cell Metab. 13: 11-22. http://dx.doi.org/10.1016/j.cmet.2010.12.008

Bennetts $\mathrm{P}$, Shen Q, Thimmesch AR, Diaz FJ, et al. (2014). Effects of ubiquinol with fluid resuscitation following haemorrhagic shock on rat lungs, diaphragm, heart and kidneys. Exp. Physiol. 99: 1007-1015. http://dx.doi.org/10.1113/expphysiol.2014.078600

Cao T, Gao Z, Gu L, Chen M, et al. (2014). AdipoR1/APPL1 potentiates the protective effects of globular adiponectin on angiotensin II-induced cardiac hypertrophy and fibrosis in neonatal rat atrial myocytes and fibroblasts. PLoS One 9: e103793. http://dx.doi.org/10.1371/journal.pone.0103793

Coimbra S, Brandao Proenca J, Santos-Silva A and Neuparth MJ (2014). Adiponectin, leptin, and chemerin in elderly patients with type 2 diabetes mellitus: a close linkage with obesity and length of the disease. Biomed. Res. Int. $2014: 1$. http://dx.doi.org/10.1155/2014/701915

Covarrubias AJ and Horng T (2014). IL-6 strikes a balance in metabolic inflammation. Cell Metab. 19: 898-899. http://dx.doi.org/10.1016/i.cmet.2014.05.009

Determan C Jr, Anderson R, Becker A, Witowski N, et al. (2014). Fed state prior to hemorrhagic shock and polytrauma in a porcine model results in altered liver transcriptomic response. PLoS One 9: e100088. http://dx.doi.org/10.1371/journal.pone.0100088

Devaraj S and Jialal I (2011). C-reactive protein polarizes human macrophages to an M1 phenotype and inhibits transformation to the M2 phenotype. Arterioscler. Thromb. Vasc. Biol. 31: 1397-1402. http://dx.doi.org/10.1161/ATVBAHA.111.225508

Douzinas EE, Betrosian A, Giamarellos-Bourboulis EJ, Tasoulis MK, et al. (2011). Hypoxemic resuscitation from hemorrhagic shock prevents lung injury and attenuates oxidative response and IL-8 overexpression. Free Radic. Biol. Med. 50: 245253. http://dx.doi.org/10.1016/j.freeradbiomed.2010.10.712

Fiaschi T, Magherini F, Gamberi T, Modesti PA, et al. (2014). Adiponectin as a tissue regenerating hormone: more than a metabolic function. Cell. Mol. Life Sci. 71: 1917-1925. http://dx.doi.org/10.1007/s00018-013-1537-4

Fry DE (2012). Sepsis, systemic inflammatory response, and multiple organ dysfunction: the mystery continues. Am. Surg. 78: $1-8$.

Gu D, Wang Z, Dou X, Zhang X, et al. (2013). Inhibition of ERK1/2 pathway suppresses adiponectin secretion via accelerating protein degradation by Ubiquitin-proteasome system: relevance to obesity-related adiponectin decline. Metabolism 62: 1137-1148. http://dx.doi.org/10.1016/j.metabol.2013.01.025

Horiuchi T, Mitoma H, Harashima S, Tsukamoto H, et al. (2010). Transmembrane TNF-alpha: structure, function and interaction with anti-TNF agents. Rheumatology 49: 1215-1228. http://dx.doi.org/10.1093/rheumatology/keq031

Jacob M and Kumar P (2014). The challenge in management of hemorrhagic shock in trauma. Med. J. Armed Forces India 70: 163-169. http://dx.doi.org/10.1016/j.mjafi.2014.03.001

Jung CH, Lee MJ, Kang YM, Jang JE, et al. (2014). Association of serum C1q/TNF-related protein-9 concentration with arterial stiffness in subjects with type 2 diabetes. J. Clin. Endocrinol. Metab. 99: E2477-2484. http://dx.doi.org/10.1210/jc.2014-2524

Kim KW, Won YL, Ko KS and Roh JW (2014). Smoking habits and neuropeptides: adiponectin, brain-derived neurotrophic factor, and leptin levels. Toxicol. Res. 30: 91-97. http://dx.doi.org/10.5487/TR.2014.30.2.091

Kishimoto T (2010). IL-6: from its discovery to clinical applications. Int. Immunol. 22: 347-352. http://dx.doi.org/10.1093/intimm/dxq030

Kumpatla S, Karuppiah K, Immaneni S, Muthukumaran P, et al. (2014). Comparison of plasma adiponectin \& certain inflammatory markers in angiographically proven coronary artery disease patients with \& without diabetes-a study from India. Indian J. Med. Res. 139: 841-850.

Lakshminarayana PH and Kahn JM (2012). First do no harm: surrogate endpoints and the lesson of beta-agonists in acute lung injury. Crit. Care 16: 314. http://dx.doi.org/10.1186/CC11392

Li CW, Xia W, Huo L, Lim SO, et al. (2012). Epithelial-mesenchymal transition induced by TNF- $\alpha$ requires NF-kB-mediated transcriptional upregulation of Twist1. Cancer Res. 72: 1290-1300. http://dx.doi.org/10.1158/0008-5472.CAN-11-3123

Li P, Jiang R, Li L, Liu C, et al. (2015). Correlation of serum adiponectin and adiponectin gene polymorphism with metabolic syndrome in Chinese adolescents. Eur. J. Clin. Nutr. 69: 62-67. http://dx.doi.org/10.1038/ejcn.2014.152

Lian K, Du C, Liu Y, Zhu D, et al. (2015). Impaired adiponectin signaling contributes to disturbed catabolism of branched-chain amino acids in diabetic mouse. Diabetes 64: 49-59. http://dx.doi.org/10.2337/db14-0312 
Lim S, Quon MJ and Koh KK (2014). Modulation of adiponectin as a potential therapeutic strategy. Atherosclerosis 233: 721 728. http://dx.doi.org/10.1016/j.atherosclerosis.2014.01.051

Lisowska A, Lisowski P, Knapp M, Tycinska A, et al. (2014). Serum adiponectin and markers of endothelial dysfunction in stable angina pectoris patients undergoing coronary artery bypass grafting (CABG). Adv. Med. Sci. 59: 245-249. http://dx.doi.org/10.1016/j.advms.2014.05.001

Liu HZ, Liu ZL, Zhao SP, Sun CZ, et al. (2014). Protective mechanism of Panax notoginseng saponins on rat hemorrhagic shock model in recovery stage. Cell Biochem. Biophys. 70: 1719-1724. http://dx.doi.org/10.1007/s12013-014-0119-x

Liu M and Liu F (2014). Regulation of adiponectin multimerization, signaling and function. Best Pract. Res. Clin. Endocrinol. Metab. 28: 25-31. http://dx.doi.org/10.1016/j.beem.2013.06.003

Luetke A, Meyers PA, Lewis I and Juergens H (2014). Osteosarcoma treatment - where do we stand? A state of the art review. Cancer Treat. Rev. 40: 523-532. http://dx.doi.org/10.1016/j.ctrv.2013.11.006

Mishra BB, Rathinam VA, Martens GW, Martinot AJ, et al. (2012). Nitric oxide controls the immunopathology of tuberculosis by inhibiting NLRP3 inflammasome-dependent processing of IL-1beta. Nat. Immunol. 14: 52-60. http://dx.doi.org/10.1038/ni.2474

Neurath MF and Finotto S (2011). IL-6 signaling in autoimmunity, chronic inflammation and inflammation-associated cancer. Cytokine Growth Factor Rev. 22: 83-89. http://dx.doi.org/10.1016/j.cytogfr.2011.02.003

Ogaki S, Taguchi K, Watanabe H, Ishima Y, et al. (2014). Carbon monoxide-bound red blood cell resuscitation ameliorates hepatic injury induced by massive hemorrhage and red blood cell resuscitation via hepatic cytochrome $\mathrm{P} 450$ protection in hemorrhagic shock rats. J. Pharm. Sci. 103: 2199-2206. http://dx.doi.org/10.1002/jps.24029

Ohashi K, Ouchi N and Matsuzawa Y (2012). Anti-inflammatory and anti-atherogenic properties of adiponectin. Biochimie 94: 2137-2142. http://dx.doi.org/10.1016/j.biochi.2012.06.008

Petrasek J, Bala S, Csak T, Lippai D, et al. (2012). IL-1 receptor antagonist ameliorates inflammasome-dependent alcoholic steatohepatitis in mice. J. Clin. Invest. 122: 3476-3489. http://dx.doi.org/10.1172/JCl60777

Phillips SA and Kung JT (2010). Mechanisms of adiponectin regulation and use as a pharmacological target. Curr. Opin. Pharmacol. 10: 676-683. http://dx.doi.org/10.1016/j.coph.2010.08.002

Qiang X, Yang WL, Wu R, Zhou M, et al. (2013). Cold-inducible RNA-binding protein (CIRP) triggers inflammatory responses in hemorrhagic shock and sepsis. Nat. Med. 19: 1489-1495. http://dx.doi.org/10.1038/nm.3368

Safai N, Eising S, Hougaard DM, Mortensen HB, et al. (2015). Levels of adiponectin and leptin at onset of type 1 diabetes have changed over time in children and adolescents. Acta Diabetol. 52: 167-174. http://dx.doi.org/10.1007/s00592-014-0630-y

Sonnier DI, Makley AT, Friend LA, Bailey SR, et al. (2011). Hemorrhagic shock induces a proinflammatory milieu in the gut lumen. J. Surg. Res. 170: 272-279. http://dx.doi.org/10.1016/j.jss.2011.03.010

Williams KB, Christmas AB, Heniford BT, Sing RF, et al. (2014). Arterial vs venous blood gas differences during hemorrhagic shock. World J. Crit. Care Med. 3: 55-60.

Wu Y and Zhou BP (2010). TNF-alpha/NF-kappaB/Snail pathway in cancer cell migration and invasion. Br. J. Cancer 102: 639-644. http://dx.doi.org/10.1038/sj.bjc.6605530

Yang C, Hou C, Zhang H, Wang D, et al. (2013). miR-126 functions as a tumor suppressor in osteosarcoma by targeting Sox2. Int. J. Mol. Sci. 15: 423-437. http://dx.doi.org/10.3390/ijms15010423

Zhao L, Luo L, Chen J, Xiao J, et al. (2014). Utilization of extracorporeal membrane oxygenation alleviates intestinal ischemiareperfusion injury in prolonged hemorrhagic shock animal model. Cell Biochem. Biophys. 70: 1733-1740. http://dx.doi.org/10.1007/s12013-014-0121-3 